\title{
IDENTIFICATION OF POSTCLASSIC MAYA CONSTELLATIONS FROM THE VENUS PAGES OF THE DRESDEN CODEX
}

\author{
Changbom Park \\ School of Physics, Korea Institute for Advanced Study, Seoul, Korea \\ Heajoo Chung \\ Institute of Iberoamerican Studies, Pusan University of Foreign Studies, \\ Busan, Korea
}

\begin{abstract}
Resumen: La civilización maya, que floreció del 1200 a.C. a 1500 d.C., dejó numerosos textos jeroglíficos sobre el calendario y observaciones astronómicos. El Códice de Dresde, en particular, contiene el más detallado de dichos antiguos legados mayas. Las páginas 24 y 46 a 50 de dicho códice describen el calendario de Venus con los augurios correspondientes. Nosotros hemos notado que éste es un calendario Venus-Solar, y nuestro trabajo se enfoca sobre la posibilidad de que estuviera hecho para trabajar en conjunción con la aparición de determinadas constelaciones en el cielo. Es a través del análisis y descripción de las páginas de Venus que proponemos que las columnas en cada página describen el movimiento de Venus respecto de constelaciones mayores, en fechas que corresponden a eventos especiales, mientras que las fechas calendáricas se incrementan horizontalmente dentro del periodo sinódico de Venus. Aquí presentamos veinte constelaciones mayas identificadas desde las páginas de Venus asumiendo que la primera fecha, en la página 46 , fue febrero 6 de 1228 . También reportamos, como entendemos, las expresiones verbales sobre el movimiento de Venus y las constelaciones.
\end{abstract}

Palabras clave: Civilización Maya, Códice de Dresde, Venus, constelaciones, k'alah, tzeni.

\begin{abstract}
Aвstract: Ancient Mayan civilization, flourished from 1200 B.C. to 1500 A.D., has left numerous hieroglyphic texts on astronomical observations and calendar. In particular, the Dresden Codex contains the most details of such ancient Mayan heritage. Page 24 and those from 46 to 50 of the Dresden Codex describe the Mayan Venus calendar along with the augural descriptions. We note that the calendar in Dresden Codex is a Venus-solar calendar. Our work focuses on the possibility that the calendar was made to work in conjunction with the periodic appearance of constellations on the sky. By analyzing the descriptions in the Venus pages, we propose that the columns in each page describe the motion of Venus with respect to major constellations at dates corresponding to special events while the calendar dates increase horizontally in the synodic period of Venus. We present twenty Mayan constellations identified from the Venus pages assuming that the first date of page 46 is February 6,1228 . We also report our understanding of verb expressions about the relative movement of constellations and Venus.
\end{abstract}

Keywords: Mayan Civilization, Dresden Codex, Venus, constellations, k'alah, tzeni.

RECLPCón: 13 de agosto de 2007

Acrptación: 1 de junio de 2009.

PARK Y CHUNG / IDENTIFICATION OF POSTCLASSIC MAYA CONSTELLATIONS 



\title{
IDENTIFICATION OF POSTCLASSIC MAYA CONSTELLATIONS FROM THE VENUS PAGES OF THE DRESDEN CODEX
}

\author{
Changbom Park \\ School of Physics, Korea Institute for Advanced Study, Seoul, Korea \\ Heajoo Chung \\ Institute of Iberoamerican Studies, \\ Pusan University of Foreign Studies, Busan, Korea
}

Ancient Mayan civilization developed in areas such as today's Mexico, Guatemala, Honduras and Belize. These areas are located from North latitude 14 to 22 and from West longitude 84 to 94 . Mayan ruins are scattered in the thick rain forests among the many rivers and lakes. Flourishing from about $1200^{1}$ B.C. to about A.D. 1500, Mayan civilization is recognized by high pyramids that have decorated house crests on the top, scientific calendars, and highly developed hieroglyphs. During the Classic period the Mayan civilization was most developed and left innumerable records on stelae, murals, altars, and ceramic vases. There are records about movement of heavenly bodies, myths of creation, and history of the life and death of the great kings, etc. All these are recorded with dates based on Mayan calendars.

When the most developed Classic Mayan period at Peten, Guatemala, had decayed, some Mayans moved into the north of the Yucatan peninsula, Mexico. At that time the Postclassic Mayan Period had begun. During the Postclassic Period Mayans preferred to write their knowledge on buckskin or bark rather than on stelae. These records are mostly practical information on their gods, daily life, and astronomical knowledge in particular. During the Postclassic period the Mayans may have made many codices, but there are only four codices remaining in existence today. The four are: Paris, Madrid, Dresden and Grolier, which were named after the places where they were found except the Grolier codex that has only 11 pages and describes changes of the Venus phases and how this relates to the gods. The biggest codex, Madrid that has 112 pages left, records that Mayans used a calendar of 260 days. Also in Madrid is a vast amount of information about scribers, hunters, merchandisers, and related information about them. In

\footnotetext{
${ }^{1}$ Archaeologically it considers that the Mayan settlement established about 2000 B.C. However, since we study problem in codex we adapted the chronology in which reflect developmental periods of Maya civilization.
}

PARK Y CHUNG / IDENTIFICATION OF POSTCLASSIC MAYA CONSTELLATIONS 
Paris, which has 24 pages left, a new Mayan calendar that starts every 20 years $^{2}$, is introduced. It also mentions the gods for each year. Of the remaining codices, the Dresden Codex was written in the most refined hieroglyphs and pictures. It also has the most complete astronomical information. It tells us about the cyclic appearance of the Venus and lunar eclipses. It also informs us about the calendar based on planet movement, prophesies, gods, and ceremonies.

In this paper, we investigate the Venus chapter that is written on page 24, and from pages 46 to $50^{3}$, of the Dresden Codex. Page 24 provides general information about the five different trajectories of Venus and the method of correction of Venus cycle. From page 46 to 50 , dates of the periodic table of the five different trajectories of Venus and related information can be found. Venus is the nearest planet from the Earth. It is the last stellar object that one can observe before dawn, and is the first object appearing at sunset. Venus has a unique cycle of visible and invisible periods that depend on its location relative to the Sun. Venus can also be observed changing its trajectory to the observer on the Earth. Because of these reasons, we suppose that the Venus was very important for the Mayans.

Venus Chapter of Dresden Codex is composed of two sections: Venus periodic table and hieroglyphic texts. Since Knorozov (1950) presented interpretation of the Dresden Codex, many investigators have tried to decipher this codex and the Venus pages were considered as Mayan calendar (Knorozov 1950; Aveny 1980 , 1992, 1997; Bricker 1992; Lounsbury 1992). But yet, besides Venus periodic table, neither the meaning of the whole hieroglyphic text nor how to actually use this Venus calendar is completely known. We will propose a way to understand structure of these pages and present the findings on Maya constellations.

\section{The Venus Pages in Dresden Codex}

\subsection{The Venus Pages}

Page 24 (Figure 1) is constituted by two parts. On the left hand side, there are hieroglyphic text that records events when Venus was visible in the East and information about the time passing. On the right hand side appears Venus cycle correction method (Lounsbury 1992:207-212; Schele \& Grube 1997: 139-143).

\footnotetext{
${ }^{2}$ This 20 year-based (19.71 years, exactly) calendar was used during the Postclassic times, especially in northern area of Yucatan Peninsula. It is known as Katun wheel.

${ }^{3}$ Dresden Codex was found partially divided into three parts. There were no page numbers on them. The codex was first numbered as pages $3-24,46-74$ and $25-45$. Actually, page 44 and 45 continue on to page 3 , therefore, the two pages should be 1 and 2 . The pages that are related with Venus are page 24 and pages 46-50. Thompson and others renumbered the pages starting from page 1, but today most investigators use the first numbering. [N. del t.: se trata de las pp. 24-29].
} 


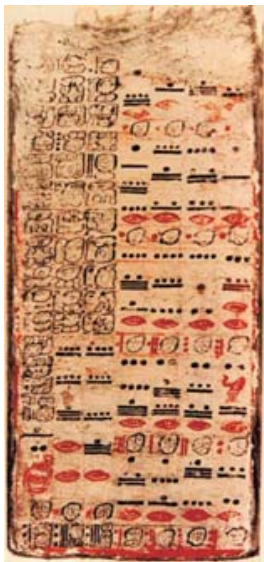

Figure 1. Page 24 of the Dresden Codex (reprinted from Códice de Dresde, 1993).

The pages from 46 to 50 (Figure 2) also have texts related with Venus and time passing. But the structure is different from page 24 . The left part of each page lists the dates of special events in the motion of Venus and contains the descriptions of the celestial events. The right part contains augural glyphs and figures. In page 24 the general information about five trajectories of Venus can be found. Meanwhile pages $46-50$ describe specific events in each phase of Venus trajectory (Schele \& Grube 1997: 142-143). We will focus on the left part of the page from 46 to 50 to understand the motion of Venus and the celestial events described. We adopt the hieroglyphic text presented at the notebook of workshop held at Texas, Austin (Schele \& Grube 1997) and a periodic table with dates, offered by Paxton (2001a \& b). 


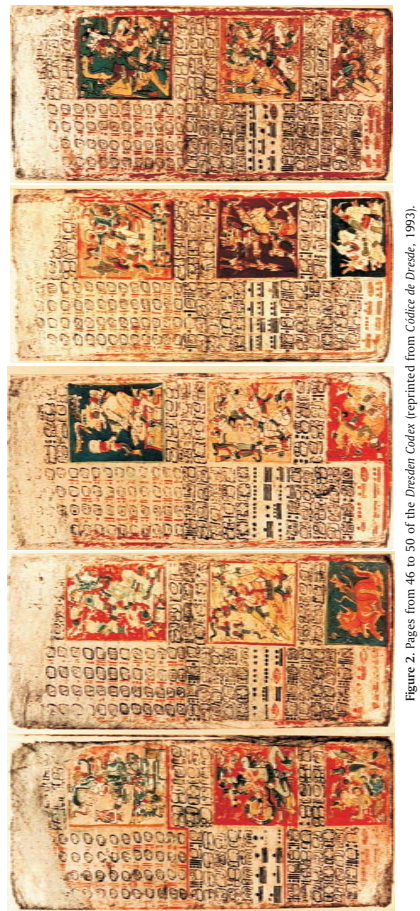




\begin{tabular}{|c|c|c|}
\hline 1 & \multirow{13}{*}{ A } & \multirow{3}{*}{ I } \\
\hline 2 & & \\
\hline 3 & & \\
\hline 4 & & \multirow{9}{*}{$\mathrm{J}$} \\
\hline 5 & & \\
\hline 6 & & \\
\hline 7 & & \\
\hline 8 & & \\
\hline 9 & & \\
\hline 10 & & \\
\hline 11 & & \\
\hline 12 & & \\
\hline 13 & & \multirow{3}{*}{$\mathrm{K}$} \\
\hline 14 & B & \\
\hline 15 & \multirow{4}{*}{ C } & \\
\hline 16 & & \multirow{7}{*}{ L } \\
\hline 17 & & \\
\hline 18 & & \\
\hline 19 & \multirow[t]{3}{*}{$\mathrm{D}$} & \\
\hline 20 & & \\
\hline 21 & & \\
\hline 22 & $E$ & \\
\hline 23 & \multirow{4}{*}{$\mathrm{F}$} & $\mathrm{M}$ \\
\hline 24 & & \\
\hline 25 & & \multirow{5}{*}{$\mathrm{N}$} \\
\hline 26 & & \\
\hline 27 & G & \\
\hline 28 & \multirow[t]{2}{*}{$\mathrm{H}$} & \\
\hline 29 & & \\
\hline
\end{tabular}

A: Dates of the last and first days of visibility of the Venus in the Tzolk'in wheel.

B: Dates of the last and first days of visibility of the Venus in the Haab cycle.

C: Description of directions of the Venus and constellations

D: Cumulative number of days

E: Dates of the event described in $\mathrm{C}$ in the Haab cycle

F: Description of directions of the Venus and constellations

G: Dates of the event described in $F$ in the Haab cycle.

$\mathrm{H}$ : Venus appearance and disappearance intervals in days

I: Augural glyphs

J: God in heaven

K: Augural glyphs

L: Venus at appearance spearing victim

M: Augural glyphs

$\mathrm{N}$ : Victim being speared

Figure 3. A schematic diagram of the Venus pages from page 46 to 50 . The row numbers are assigned on the left.

Figure 3 is a schematic diagram showing the structure of the pages, and the description of each panel is given in the caption. Panel A consists of four columns of 13 rows of Tzolk'in ${ }^{4}$ date and Panel B shows Haab ${ }^{5}$ date. The combination of panels $A$ and $B$ gives the specific dates of the last and first days of Venus visibility for all 13 Venus cycles. Panels $\mathrm{C}$ and $\mathrm{F}$ describe the motion of Venus with respect to the four celestial directions and constellations in the sky. Panel D lists the accumulated number of days from the beginning of the calendar to the current column within a Venus cycle, and panel $\mathrm{H}$ shows the interval of days to the next

\footnotetext{
${ }^{4}$ Tzolk'in is a calendar system based on 13 numbers and 20 names. It shows 260 days calendar.

${ }^{5}$ Haab is another calendar system based on 20 numbers and 18 names, add 5 days. It forms 365 days calendar.
}

PARK Y CHUNG / IDENTIFICATION OF POSTCLASSIC MAYA CONSTELLATIONS 
column. The dates written in panels $\mathrm{E}$ and $\mathrm{G}$ indicate days ${ }^{6}$ in Haab cycle when events described in $\mathrm{C}$ and $\mathrm{F}$ happened. On the right on Panel $\mathrm{J}$ there is a drawing of a God who sits on the "sky band ${ }^{7}$ of a God attacking on Panel L, and of victims on Panel $\mathrm{N}$. Between these figures in panels I, K and $\mathrm{M}$ are some hieroglyphic text. The left part describes time passing and heavenly bodies changing while the right part depicts some unidentified figures. This insinuates that the left part is the description of logical process and the right part is dedicated to symbolic warnings of events. But the relationship of the two parts is still in question.

\subsection{The Venus Cycle and the Grand Venus Cycle}

The Venus pages of Dresden Codex are comprised of 5 pages. They have the same structure but present different contents. According to Aveny (1999: 75), if we observe the morning Venus everyday at dawn, different points can be noticed for the location of Venus when it becomes invisible. Connecting these points allows us to draw the Venus trajectory. From these we can recognize five different Venus trajectories. Each of the Venus pages represents one Venus synodic year and it repeats 5 times over pages 46-50, corresponding to the five trajectories. On each page a Venus synodic year is split into four phases (Aveny 1999: 179), corresponding to: a) visibility as morning star (236 days), b) invisibility near superior conjunction (90 days), c) visibility as evening star (250 days), and d) invisibility near inferior conjunction ( 8 days). These intervals repeat on each page. The four dates at the top of each page are the dates of the changing phases of the Venus synodic year (Paxton 2001: 102): the first column (3Kib 4Yaxk'in in page 46, for example) is the last date of the morning star during 236 days; the second column (2Kimi 14 Sak in page 46 ) is the first day as an evening star after invisible 90 days; the third column (5Kib 19Sek in page 46) is the last date of 250 days as an evening star; and the fourth column (13K'an 7Xul in page 46) is the first date as a morning star after invisible 8 days (see Figure 4 and Table 3 ).

Panel D of each page lists the accumulative numbers of days. Starting from the first column of page 46 , panel D lists $236,236+90=326,326+250=576$, $576+8=584,584+236=820,820+90=910,910+250=1160,1160+8=1168$, and so on. The accumulation continues until the number of days reaches five

\footnotetext{
${ }^{6}$ The Mayans used various calendar systems: the Long Count based on 1,872,000 days, Tzolk'in based on 260 days, Haab based on 365 days, and the Katun system based on 7,200 days. A specific date can be designated by any system. During the Classic Period the Mayans recorded dates using the Long Count, Tzolk'in, Haab and added lunar calendar. Since the Long Count system covers more than 5,000 years, a certain Long Count date can be seen only one time during the Maya civilization. Along the Postclassic Period the Katun system was used. In the Dresden codex we can find the Tzolk'in and Haab system. Even though Tzolk'in and Haab combination date was usually used, a Tzolk'in or a Haab date can individually designate a specific day.

'The 'sky band' is a style of decoration frame in Mayan relief. It usually contains hieroglyphic characters of the heavenly bodies such as Venus, the Moon, the Sun, etc.
} 
Venus years, $5 \times 584$ days $=2,920$ days on page 50 . The panel $\mathrm{A}$ is a periodic table of the Venus cycle. One Venus cycle corresponds to each row (marked by 20 dates) in panel A from page 46 to 50 . And the next Venus cycle starts again on page 46 from the following row. By this process 13 rows of the calendar cover the Venus cycle thirteen times. Therefore, the Venus pages are designed to be used for 13 Venus cycles covering $13 \times 2,920$ days $=37,960$ days or about 104 years, the Grand Venus cycle (Aveny 1980: 184-190, 1999: 169-194; Paxton 2001: 101-108).

One Venus cycle, 2,920 days, is close to eight years since the total number of days in eight years is $8 \times 365.2422$ days $=2921.938$ days. Since the Venus cycle is nearly an integer multiple of the terrestrial year, nearly the same situation repeats on the sky (both Venus and constellations) in each Venus cycle, meaning every 8 years. A constellation seen at a specific date and location in a Venus cycle appears again at nearly the same time and the same direction in the next cycle. However, the difference between the Venus cycle and the eight years Earth revolution period is $2,920-2,921.938=-1.938$ days per Venus cycle. When 13 Venus cycles have passed, the difference between the calendar and the actual period of the celestial events amounts to $13 \times-1.938$ days $=-25.19$ days. This means, the calendar is 25.19 days short with respect to the new beginning of the replay of the heavenly events, after 13 Venus cycles have passed.

On the other hand, the difference between the Mayan Venus year of 584 days and the true synodic year of Venus (583.92 days) also becomes important. The error in one Venus cycle with respect to the true synodic period is 584-583.92 $=0.08$ day, and it will accumulate 5 times after one Venus cycle has completed. After one Grand cycle the error in the Venus calendar accumulates by $13 \times 5 \times$ 0.08 days $=+5.2$ days. That is, the calendar is 5.2 days too long to keep the true Venus phase. On the other hand, the relative location of the Venus with respect to the constellations in the sky, changes by an amount corresponding to $25.2+5.2=30.4$ days. Therefore, if the Mayan Venus calendar was to be used repeatedly keeping the Venus cycle correctly, the calendar needs to be corrected by about 5 days after a Grand cycle. So then, if the Mayan Venus calendar in Dresden Codex was used with proper corrections for the beginning date after every Grand cycle, it could be used over and over again. But if the calendar was to keep up with the constellations in the sky, the calendar requires a significant correction of about 30 days after used for one Grand cycle and can be used only for a finite duration of time (one or two Grand cycles, for example).

\subsection{Analysis of the Contents in Panels $C$ and F}

Since this paper has focus on identifying the Mayan constellations, we will analyze only the left part of the Venus pages from pages 46 to 50 , which is thought to be the records of celestial events and times; Figure 4 and Table 3 show the simplified deciphered text of these pages. 
Table 1. Identification of Mayan constellations and the corresponding glyphs.

When more than one name in the identified modern constellation list is given, the first name is the major location of the Mayan constellation.

\begin{tabular}{|c|c|c|c|}
\hline page & Hieroglyphs & Mayan Name & Modern Constellations \\
\hline \multirow{4}{*}{46} & 369 & Ulum (turkey) & Auriga \\
\hline & 89 & Sinan (scorpion) & Pegasus-Aquarius \\
\hline & & Chak? (Great?) & $\begin{array}{l}\text { Aquarius-Pegasus-Piscis } \\
\text { Austrinus }\end{array}$ \\
\hline & CE & Kimi-1 (Death God-1) & Virgo - Bootes \\
\hline \multirow{4}{*}{47} & 28 & Vulture? & Cygnus \\
\hline & Q & God? & Virgo - Corvus \\
\hline & 몽 & 13Kan (13 Sky) & Centaurus \\
\hline & 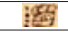 & 4Pawahtun & Orion - Taurus \\
\hline \multirow{4}{*}{48} & PA & Kin Ahau (Sun Lord) & Ursa Major \\
\hline & & 6Yich & Aries - Pleiades \\
\hline & 929 & Ak'ab Ahau (Night Lord) & Eridanus - Taurus \\
\hline & 501 & $\begin{array}{l}\text { Ixik Uh Ahau (Lady Moon } \\
\text { Lord) }\end{array}$ & Aquila \\
\hline \multirow{4}{*}{49} & $\sin$ & $?$ & Andromeda \\
\hline & & Kimi-2 (Death God-2) & Ophiucus - Scorpius \\
\hline & Et? & Kawil & Sagittarius \\
\hline & 87 & 1Ahau & Leo \\
\hline \multirow{4}{*}{50} & EQ] & Nal (Maize God) & Corona Borealis - Hercules \\
\hline & (63) & God L & Canis Minor - Gemini \\
\hline & 28 & Wuk? (armadillo?) & Vela - Hydra \\
\hline & (20) & Ain (crocodile) & Pegasus - Pisces \\
\hline
\end{tabular}

In each column of a page there are four dates in Tzolk'in and Haab cycle. The first column of page 46 lists 3 Kib (Tzolk'in, panel A) 4 Yaxk'in (Haab, panel B), 9 Sak (Haab, panel E), and 19 K'ayab (Haab, panel G). The first date 3 Kib 4 Yaxk'in (date given by Tzolk'in and Haab in combination) is considered to be a specific date for an event in the first column. Besides this date, there are two Haab dates related with two phrases: one begins with the verb 'tie' (panel $\mathrm{C}$ ) and the other begins with the verb 'feed' (panel F). When the verb 'tie' and 'feed' appear in panels $C$ and F, four celestial directions and four different figure names are accompanied. Between them 
Table 2. Actual situation corresponding to the expression on the movement of Venus from page 46 to 50 of the Dresden Codex. C1, C2, C3, and C4 are constellations.

\begin{tabular}{|l|l|l|}
\hline & Expression in Dresden Codex & Actual Situation \\
\hline (a) & Venus ties to the North, C1 & $\begin{array}{l}\text { The Evening Venus is setting, and C1 is set- } \\
\text { ting together in Northwest }\end{array}$ \\
\hline & C1 feeds Venus at the North & $\begin{array}{l}\text { (220 days later) The Evening Venus is setting, } \\
\text { and C1 is rising in Northeast }\end{array}$ \\
\hline (b) & Venus ties to the West, C2 & $\begin{array}{l}\text { The Evening Venus is setting in the West, } \\
\text { and C2 is rising in East }\end{array}$ \\
\hline (c) & Venus ties to the South, C3 & $\begin{array}{l}\text { (380 days later) The Morning Venus is rising, } \\
\text { and C2 is setting in West }\end{array}$ \\
\hline together in Southeast
\end{tabular}

there are numbers of days corresponding to each phase of a Venus calendar year (panel D and $\mathrm{H}$ ).

It should be noticed that a figure name and a direction used in 'tie' verb phrase repeat in the 'feed' verb phrase in the next column. For example, in panel C of the first column on page 46 one can find "tie north Ulum ${ }^{8}$ Venus" and in panel F of second column "Ulum feed Venus north". The figure name Ulum and the direction north were repeated on both phrases. In the same manner, the second and third columns translate "tie west Sinan Venus" and "Sinan feed Venus west." This pairing across columns can be seen throughout the whole cycle from page 46 to 50 , and the figure named in panel $\mathrm{C}$ of the last column of the last page (page 50) links to that in panel $\mathrm{F}$ of the first column of the first page (page 46) (see Figure $2 \& 4$ ). Since the figure name is something that can be compared with the four directions and Venus, one can postulate that it is a name of a constellation that could be observed in the sky at both dates given in panels $\mathrm{E}$ and $\mathrm{G}$. We think this assumption is logical because the Venus calendar is made to work in conjunction with the terrestrial year (i.e. 1 Venus cycle $=5$ Venus calendar years $\approx 8$ terrestrial years), which is the period of the appearance of constellations on the sky. So if all figures are identified with some known constellations, they can be used to find out the specific situation in the sky at the time corresponding to the description in panel $\mathrm{C}$ or $\mathrm{F}$.

\footnotetext{
${ }^{8}$ If a figure designates a constellation, it will be a proper noun. So we used Mayan words directly
} without translation. 
Table 3. Contents of the Dresden codex and the corresponding meaning when the first date of the calendar is February 6, 1228. Page 46.

Key to abbreviation:

GS: Great Star, means the Venus, EV: evening Venus, MV: morning Venus;

$\mathrm{N}$ : north, S: south, W: west, E: east;

Aur: Auriga, Ori: Orion, Aqr: Aquarius, Peg: Pegasus, PsA: Piscis Austrinus, Vir: Virgo, Boo: Bootes, Psc: Pisces, Cyg: Cygnus, Aql: Aguila, Cen: Centaurus, Tau: Taurus, UMa: Ursa Major, Leo: Leo, Ari: Aries, Pleiades: Pleiades, Eri: Eridanus, Sgr: Sagittarius, And: Andromeda, Crv: Corvus, Oph: Ophiucus; Sco: Scorpius, Hya: Hydra; CrB: Corona Borealis, Her: Hercules, CMi: Canis Minor, Gem: Gemini, Vel: Vela;

"EV setting with Aur in NW" means "Evening Venus is setting and Auriga, is setting together in Northwest"

"EV setting in W when Vir rising in E" means "Evening Venus is setting and Virgo is rising in East" "MV rising when Vir setting in W" means "Morning Venus is rising and Virgo is setting in West"

Table 3. (continued) Page 46

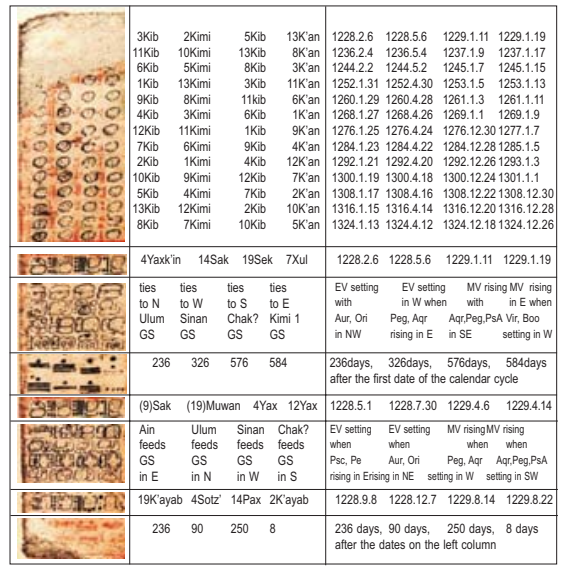


Table 3. (continued) Page 47

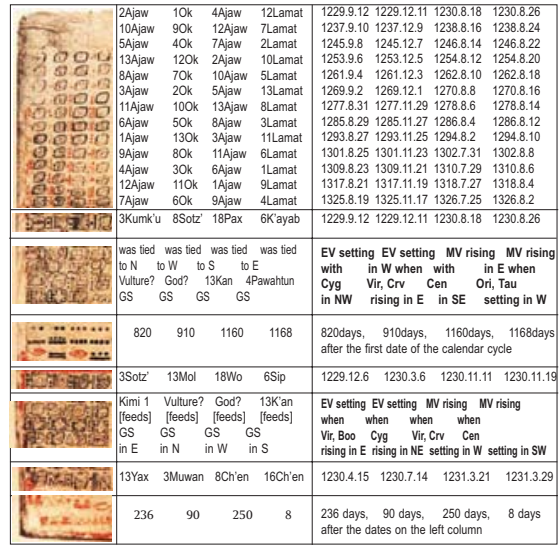


Table 3. (continued) Page 48

\begin{tabular}{|c|c|c|}
\hline 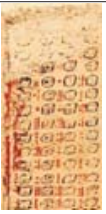 & 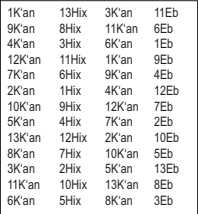 & $\begin{array}{llll}1231.4 .19 & 1231.7 .18 & 1232.3 .24 & 1232.4 .1 \\
1239.4 .17 & 1239.7 .16 & 1240.3 .22 & 1240.3 .30 \\
1247.4 .15 & 1247.7 .14 & 1248.3 .20 & 1248.3 .28 \\
1255.4 .13 & 1255.7 .12 & 1256.3 .18 & 1256.3 .26 \\
1263.4 .11 & 1263.7 .10 & 1264.3 .16 & 1264.3 .24 \\
1271.4 .9 & 1271.7 .8 & 1272.3 .14 & 1272.3 .22 \\
1279.4 .7 & 1279.7 .6 & 1280.3 .12 & 1280.3 .20 \\
1287.4 .5 & 1287.7 .4 & 1288.3 .10 & 1288.3 .18 \\
1295.4 .3 & 1295.7 .2 & 1296.3 .8 & 1296.3 .16 \\
1303.4 .1 & 1303.6 .30 & 1304.3 .6 & 1304.3 .14 \\
1311.3 .30 & 1311.6 .28 & 1312.3 .4 & 1312.3 .12 \\
1319.3 .28 & 1319.6 .26 & 1320.3 .2 & 1320.3 .10 \\
1327.3 .26 & 1327.6 .24 & 1328.2 .29 & 1328.3 .8\end{array}$ \\
\hline & 17Yax 7Muwan 12Ch'en OYax & $\begin{array}{llll}1234.6 .30 & 1234.9 .28 & 1235.6 .5 & 1235.6 .13\end{array}$ \\
\hline & $\begin{array}{l}\text { was tied was tied was tied was tied } \\
\text { to } \mathrm{N} \text { to } \mathrm{W} \text { to } \mathrm{S} \text { to } \mathrm{E} \\
\text { Kin Ahau } 6 \text { Yich Ak'ab Ahau Ixik Uh Ahau } \\
\text { GS GS GS GS }\end{array}$ & $\begin{array}{l}\text { EV setting EV setting MV rising MV rising } \\
\text { with in W when with in E when } \\
\text { UMa Ari, Pleiades Eri, Tau Aql } \\
\text { in NW rising in E in SE setting in W }\end{array}$ \\
\hline & $1404 \quad 1294 \quad 1744 \quad 1752$ & $\begin{array}{l}\text { 1404days, } 1294 \text { days, } 1744 \text { days, } 1752 \text { days } \\
\text { after the first date of the calendar cycle }\end{array}$ \\
\hline & 2Muwan 7Pop 17 Mak 5Kankin & $\begin{array}{llll}1231.7 .13 & 1231.10 .11 & 1232.6 .17 & 1232.6 .25\end{array}$ \\
\hline 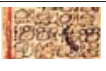 & $\begin{array}{l}\text { feeds feeds feeds feeds } \\
\text { 4Pawahtun Kin Ahau 6Yich Akab Ahau } \\
\text { in } \mathrm{E} \quad \text { in } \mathrm{N} \text { in } \mathrm{W} \text { in } \mathrm{S}\end{array}$ & $\begin{array}{l}\text { EV setting EV setting MV rising MV rising } \\
\text { when when when when } \\
\text { Tau, Ori UMa Ari, Pleiades Eri, Tau } \\
\text { rising in E rising in NE setting in W setting in SW }\end{array}$ \\
\hline 13808:2910 & 17Yaxk'in 2 Wo & $1232.10 .25 \quad 1232.11 .2$ \\
\hline 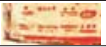 & 250 & $\begin{array}{l}236 \text { days, } 90 \text { days, } 250 \text { days, } \\
\text { after the dates on the left column }\end{array}$ \\
\hline
\end{tabular}


Table 3. (continued) Page 49

\begin{tabular}{|c|c|c|}
\hline & 13Lamat 12Etz'nab 2Lamat 10Kib & $\begin{array}{llll}1232.11 .23 & 1233.2 .21 & 1233.10 .29 & 1233.11 .6\end{array}$ \\
\hline & 7Etz'nab 10Lamat 5Kib & 1241.10.27 1241.11 .4 \\
\hline & 5Lamat $13 \mathrm{Kib}$ & $1249.10 .25 \quad 1249.11 .2$ \\
\hline & 10Etźnab 13Lamat 8Kib & $1257.10 .23 \quad 1257.10 .31$ \\
\hline 29.6 & 6Lamat 5Etz'nab 8Lamat $3 \mathrm{Kib}$ & $1265.10 .21 \quad 1265.10 .29$ \\
\hline 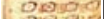 & 1Lamat 13Etz'nab 3Lamat 11Kib & $1273.10 .19 \quad 1273.10 .27$ \\
\hline 12 & 9Lamat 8Etz'nab 11Lamat 6Kib & $1281.10 .17 \quad 1281.10 .25$ \\
\hline & 4Lamat 3 Etz'nab 6Lamat $1 \mathrm{Kib}$ & $1289.10 .15 \quad 1289.10 .23$ \\
\hline & 12Lamat 11Etz'nab & $1297.10 .13 \quad 1297.10 .21$ \\
\hline & 9Lamat 4 Kib & $1305.10 .11 \quad 1305.10 .19$ \\
\hline 213 & 9Lamat 12Kib & $1313.10 .9 \quad 1313.10 .17$ \\
\hline & 12Lamat $7 \mathrm{Kib}$ & $1320.11 .1 \quad 1321.1 .30$ \\
\hline & 5Lamat 4Etz'nab 7 Lamat $2 \mathrm{Kib}$ & 1328.10 .301329 .1 .28 \\
\hline & $11 \mathrm{Sip} 1 \mathrm{Mol}$ & $1232.11 .231233 .2 .21 \quad 1233.10 .291233 .11 .6$ \\
\hline & \begin{tabular}{|llll} 
was tied & was tied was tied was tied \\
To $N$ & to W & to $S$ & to $\mathrm{E}$ \\
?4 & Kimi 2 & Kawil & 1 Ahau \\
GS & GS & GS & GS
\end{tabular} & 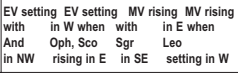 \\
\hline 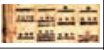 & $\begin{array}{llll}1988 & 2078 & 2328 & 2336\end{array}$ & $\begin{array}{l}\text { 1988days, } 2078 \text { days, } 2328 \text { days, } 2336 \text { days } \\
\text { after the first date of the calendar cycle }\end{array}$ \\
\hline & 16Yaxk'in 6Keh 11Xul 19Xul & $\begin{array}{llll}1233.2 .16 & 1233.5 .17 & 1234.1 .22 & 1234.1 .30\end{array}$ \\
\hline 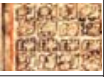 & \begin{tabular}{llll} 
feeds feeds & feeds & feeds \\
lxik Uh Ahau ?4 & \multicolumn{1}{c}{ Kimi 2 K'awil } \\
GS & GS & GS & GS \\
in $E$ & in N & in W & in S
\end{tabular} & $\begin{array}{l}\text { EV setting EV setting MV rising MV rising } \\
\text { when when when when } \\
\text { Aql, Sgr And Oph, Sco Sgr } \\
\text { rising in E rising in NE setting in W setting in SW }\end{array}$ \\
\hline If(2Mr). & 6K'ank'in 16KumK'u 1Mak & $1233.6 .26 \quad 1233.9 .24 \quad 1234.6 .1$ \\
\hline 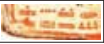 & 2508 & $\begin{array}{l}236 \text { days, } 90 \text { days, } 250 \text { days, } 8 \text { days } \\
\text { after the dates on the left column }\end{array}$ \\
\hline
\end{tabular}

PARK Y CHUNG / IDENTIFICATION OF POSTCLASSIC MAYA CONSTELLATIONS 
Table 3. (continued) Page 50

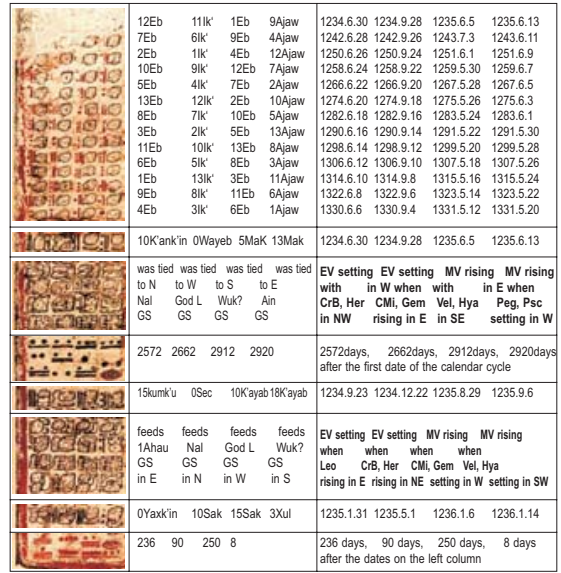


Let us first look at the dates in each column (Figure 4). Each column begins with the date when Venus is almost invisible since it is a pivot day of the changing phase of Venus with respect to the Sun. So then it needs to find another day to observe celestial events. The second date in the first column of page 46 is 9 Sak. It is the date after 85 days from the first date 4 Yaxk'in. On this day it is possible to see both Venus and constellations clearly, so that the second date could be when the 'tie' event happened. From the second date 9 Sak to the third date 19 K'ayab 130 days are passed. In the same manner, the 'feed' event could happen at the third date. (see Tzolk'in and Haab tables in Appendix).

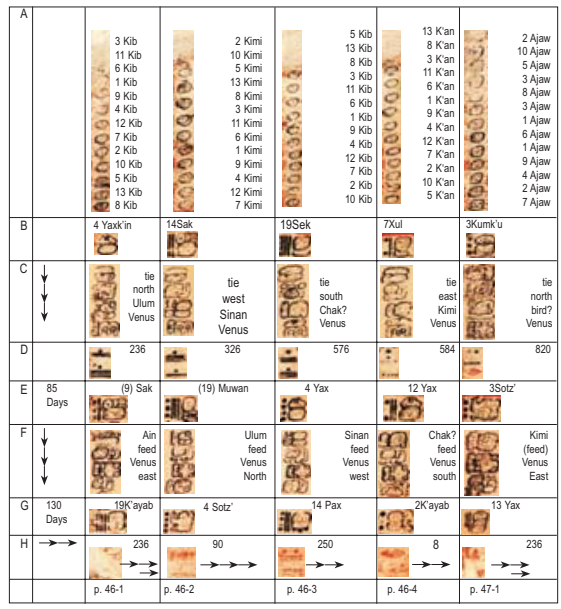

Figure 4. Page 46 and the first column of page 47

A: Venus phase table. B: Haab calendar C: "tie" action phrase. D: accumulated interval days from previous column. E: Haab calendar. F: "feed" action phrase. G: Haab calendar. H: number of days from the previous column. 
As we have mentioned previously, a figure appearing at the 'tie' action also appears at the 'feed' action in the column following. Let's see when we can observe the same figure in different action. In page 46, it was 9 Sak (first column, section E) when the event "tie north Ulum Venus" happened. The companion event "Ulum feed Venus north" happened at 4 Sotz' (second column, section G). There are 220 days' difference between 9 Sak and 4 Sotz'. We have calculated already that it needs 130 days to observe "feed" action after seeing "tie" action. Here it passed 90 days more because the "feed" action of Ulum can be observed not at the same but at the next column. The time distance between the first and second column was of 90 days (Figure 4). The accumulative days passing, expressed by solar cycle based on the Haab calendar, indicates that Ulum in the 'feed' action should be observed 220 days after the 'tie' action. In the same manner, there are 380 days interval between two Sinan events, 138 days between Chak? events, and 366 days between Kimi events. There are four pairs of celestial events in each page. The schematic diagram in Figure 5 shows the time distance between the paired events.

\section{Identification of the Maya Constellations}

\subsection{Theory of Visibility, and Morning and Evening Star}

The position of Venus in the sky is determined by its location relative to the Earth. In addition to this, the visibility and appearance of Venus as a morning or evening star are determined by the relative locations of Venus, Earth and the Sun. Venus orbits around the Sun in a nearly circular orbit, and appears to move back and forth across the Sun, to an observer on the Earth. The Earth also orbits around the Sun, and the observer on the Earth sees the Sun migrating slowly (nearly $1^{\circ}$ per day) across the celestial sphere. This path is called the ecliptic, and actually is the intersection between the orbital plane of the Earth and the celestial sphere. The ecliptic coordinate system, used to designate the location of a celestial body in the sky, is a frame in which the equator of the system is set to the ecliptic. Since the orbital plane of Venus inclines only $3.4^{\circ}$ from the ecliptic, one can approximate the position of Venus with respect to the Sun by using the difference between their longitudes in the ecliptic coordinate system. When the ecliptic longitude of Venus is larger than that of the Sun, Venus is an evening star because it sets after the Sun does. When its longitude is smaller, Venus is a morning star. When the difference is too small (less than about $10^{\circ}$ ), it is very difficult to observe Venus due to great brilliance of the Sun (see Figure 6)

We will see the arrangement of celestial bodies in the night sky below. To do that, we need to specify the dates of events. Previously, we have shown that the Mayan Venus calendar in Dresden Codex could be used over and over again with some corrections after 13 Venus cycles or one Grand cycle. It is then true that the beginning date of the calendar can be chosen as any of the first dates of the Grand 
a) 220 days interval between two "Ulum" events in panel $\mathrm{C}$ of the $1^{\text {st }}$ column and in panel $\mathrm{F}$ of the $2^{\text {nd }}$ column, at page 46 .

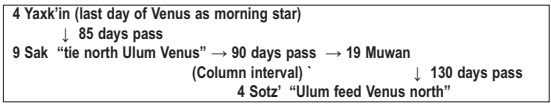

b) 380 days interval between two "Sinan" events in panel C of the $2^{\text {nd }}$ column and in panel $\mathrm{F}$ of the $3^{\text {rd }}$ column, at page 46.

14 Sak (first day of Venus as evening star)

$\downarrow$ after 85 days

19 Muwan "tie west Sinan Venus" $\rightarrow 250$ days pass $\rightarrow 4$ Yax

(Column interval) $\quad \downarrow 130$ days pass

14 Pax "Sinan feed Venus west"

c) 138 days interval between two "Chak?" events in panel $\mathrm{C}$ of the $3^{\text {rd }}$ column and in panel $\mathrm{F}$ of the $4^{\text {th }}$ column, at page 46 .

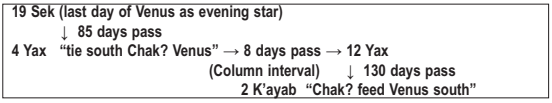

d) 366 days interval between two "Kimi" events in panel $\mathrm{C}$ of the $4^{\text {th }}$ column at page 46 and in panel $\mathrm{F}$ of the $1^{\text {st }}$ column at page 47.

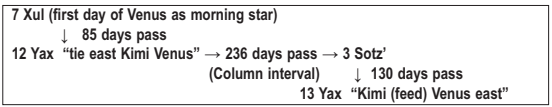

Figure 5. Diagrams of the time interval that permit observation of the same constellations.

Each diagram shows that the same constellation at the same direction becomes visible after some time interval of $220,380,138$ or 366 days. 
cycles. Since this codex was written during the Postclassic Period that flourished during 1000-1400 A.D., in this paper we adopt Paxton's (2001: 101) claim that the last date of the calendar, 1Ajaw 13Mak, corresponds to June 15, 1227. If this is so, then the first date of page 46, 3Kib 4Yaxk'in, corresponds to February 6, 1228. We will use this day as the first day of the Venus calendar in page 46 to demonstrate how the (Postclassic) constellations can be identified. Note that our identification of constellations will change after a few Grand cycles if the calendar is corrected for repeated usage only to keep up with the synodic period of the Venus. However, our constellation-finding logic itself can be applied to any Grand cycle.

On page 46 , which describes the first Venus calendar year, the four first dates of the four columns are 3Kib 4Yaxk'in, 2Kimi 14Sak, 5Kib 19Sek, and 13K'an $7 \mathrm{Xul}$. They correspond to days when Venus was seen last as a morning star (February 6, 1228), first as an evening star (May 6, 1228), last as an evening star (January 11, 1229), and first as a morning star (January 19, 1229). Figure 6 shows the variation of the difference between ecliptic longitudes of Venus and the Sun as a function of ecliptic longitude of Venus from February 6, 1228 (see the arrow in Figure 6) to September 11, 1229, which is the period covered by page 46 . Each small dot represents one day. The four large circles are the first dates in the four columns on panels A and B. It can be immediately noticed that Venus is very close to the Sun at those dates.

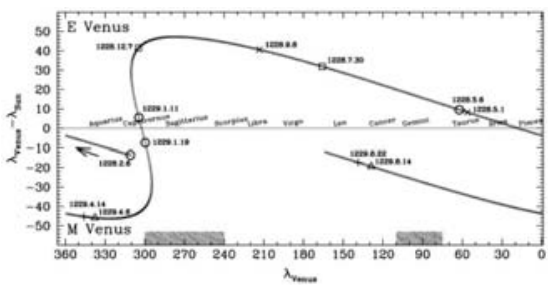

Figure 6. The difference in ecliptic longitude of Venus and the Sun as a function of that of Venus from Feb. 6, 1228 (see the arrow) to Sep. 11, 1229, which is one period covered by page 46. One small dot is plotted each day. The four large circles are the first four dates given in the columns of page 46 , and other symbols mark the second and third dates. When the ecliptic longitude difference is positive, Venus is the Evening star (E Venus) and when it is negative, Venus is the Morning star (M Venus). The shaded regions in the ecliptic longitude are where the Milky Way passes, and the 12 zodiac constellations are marked. Dates are written in a form of year-month-day. 
Figure 6 also shows the 12 zodiac constellations, which follow the ecliptic. When Venus is the evening star $\left(\lambda_{\text {Venus }}-\lambda_{\text {Sun }}>0\right)$, the constellations on the leftward side (at higher ecliptic longitude) of Venus are visible at dusk. When Venus is the morning star, the constellations at lower longitudes can be observed at dawn.

\subsection{Identification of Constellations}

To identify constellations based on what is written in panels $\mathrm{C}$ and $\mathrm{F}$, we need to understand the situation when the same constellations can be observed at two different times. Constellations in the night sky change as the Sun moves along the ecliptic circle by about $1^{\circ}$ per day. When one takes the Sun as the reference point instead, stars move about $1^{\circ}$ per day to the west and set $1^{\circ}$ (or 4 minutes) earlier everyday. A constellation seen at a specific time appears again in the opposite side of the sky after about 183 days, and it appears in the same direction after 365 days. The Sun also makes a diurnal motion to complete a circle in about 24 hours due to the rotation of the Earth. A constellation appears again in the opposite side of the sky after about 12 hours, and it appears in the same direction after 24 hours.

As we have seen previously, the time differences between the dates of the paired events (see Figure 4) are 220, 380, 138, and 366 days. Over these time periods, constellations move across the sky. The situation in each of the four pairs of dates on a page can be described as the following:

a) At the date of the 'tie' action of the first column Venus is an evening star, and 220 days later it is still an evening star. A constellation in the west above the horizon will move by $217^{\circ}$, and will be seen in the East above the horizon again after 220 days.

b) A constellation seen at the date of the 'tie' action in the second column will appear again at roughly the same direction after making $375^{\circ}$ rotation during 380 days. Venus changes to a morning star from an evening star.

c) At the date of the 'tie' action of the third column, Venus was a morning star and remained so at the date of the 'feed' action day of the next column. A constellation in the East will move by $136^{\circ}$ during 138 days, and will be visible in the West.

d) A constellation seen at the date of the 'tie' action of the fourth column will appear at nearly the same direction after making $361^{\circ}$ rotation during 366 day. Venus changes to an evening star from a morning star.

When comparing the two skies at the dates corresponding to the events in a pair, we should choose particular times of the day as well since the sky is turning constantly. We have chosen a particular time of the day when Venus is just rising in the case of the Morning Venus, or a particular time when the setting Venus and the major constellations are first visible to the eyes in the case of the Evening Venus. Both cases are the times when Venus is first visible in the sky. 
Once we fix the first day of the Grand cycle, we can get all the exact dates of events in the Venus pages. We can identify Mayan constellations mentioned in panel $\mathrm{C}$ and $\mathrm{F}$ in pairs, using the dates written in panels $\mathrm{E}$ and $\mathrm{G}$. Let us see the actual constellation maps at the dates mentioned in pairs. The first four pairs appearing in page 46 are (dates adopted from Paxton 2001):

a) Ulum at May 1, 1228 (Evening Venus) and December 7, 1228 (Evening Venus)

b) Sinan at July 30, 1228 (Evening Venus) and August 14, 1229 (Morning Venus)

c) Chak? at April 6, 1229 (Morning Venus) and August 22, 1229 (Morning Venus)

d) Kimi at April 14, 1229 (Morning Venus) and April 15, 1230 (Evening Venus)

The left sky map of Figure 7 shows the sky in the evening of May 1, 1228 when Venus was first visible. The right map is the sky in the evening of December 7,1228 when Venus was first visible. One can find that the region around Auriga and Orion was visible at both days which were 220 days apart, and can conclude that the word Ulum must mean this part of the sky. This procedure was applied to the remaining three cases, and the results are shown in Figures 8,9 , and 10 . For each one of all 20 pairs from page 46 to 50 we have checked if there is a part of the sky that can be seen at both dates when the same name is stated in a pair. Then we have selected major constellations to designate the common part of the sky that can be seen in two paired events. It is reassuring that such common part of the sky exists for every pair. When we look for the common parts, we neglect the region near the north celestial pole that is always visible. We interpret that the North direction mentioned in the text indicates Northwest or Northeast, and the South indicates Southeast or Southwest.

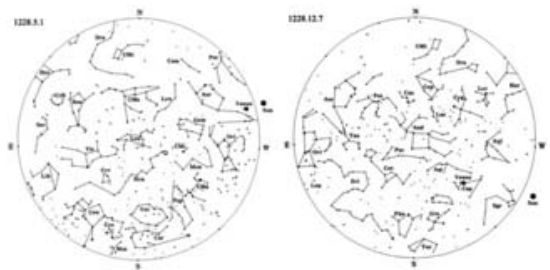

Figure 7. Comparison of skies of pairing days in page 46. The zenith is at the center of each map, and the circle with the four direction marks denotes the horizon. The REDSHIFT 5 software package is used to show the sky, and the observer is set to locate at W91 $42^{\prime}, N 17^{\circ} 6^{\prime}$, which is roughly the location of Postclassic Mayan site, Chichen Itza. 
In the evening of May $1^{\text {st }}, 1228$, Venus was seen west close to horizon and in the north-western sky near Auriga (Aur). In the evening of December 7, 1228, Venus was seen west, and the same constellations were visible at the opposite direction, northeastern sky. A constellation 'Ulum' is named at both days.

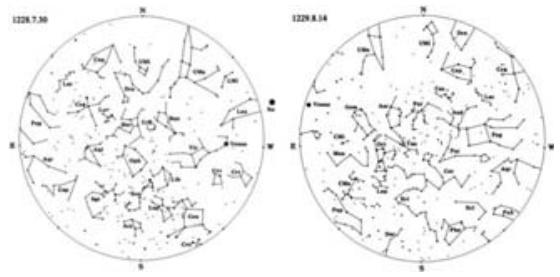

Figure 8. Venus and constellations on the sky in the evening of July 30,1228 , and in the morning of August 14, 1229. In the evening of July 30, 1228, Venus was west and the region near Aquarius (Aqr) and Pegasus (Peg) appears at the opposite direction, east. In the morning of August 14, 1229 Venus was east, and the same region was at the opposite direction, west (besides the part near the north celestial pole). A constellation 'Sinan' is named at both days.

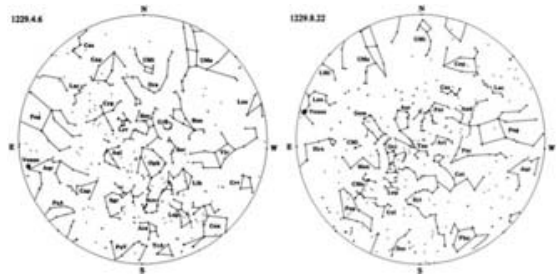

Figure 9. In the morning of April 6, 1229 Venus was at east near from horizon, and the region near Aquaris (Aqr), Pegasus(Peg), and Piscis Austrinus (PsA) was visible at the southeast direction. In the morning of August 22, 1229 Venus was visible still at east, but the same region was at the opposite direction, west and southwest (besides the part near the north celestial pole). A constellation 'Chak?' is named at both days.

PARK Y CHUNG / IDENTIFICATION OF POSTCLASSIC MAYA CONSTELLATIONS 


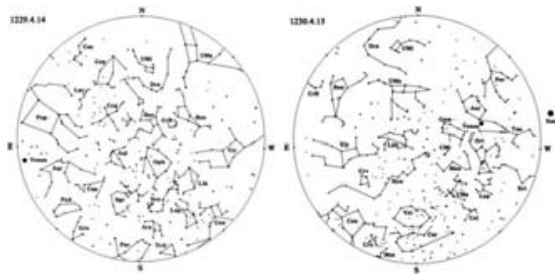

Figure 10. Mayan constellation map in the equatorial coordinate system. Hammer-Aitoff projection (Colabretta \& Greissen 2002) of the whole sky. Plotted are 4,124 stars brighter than the visual magnitude of 5.8. Stars are connected to show the modern constellations. Constant declination and right ascension lines are drawn at every 10 and 20 degree intervals, respectively. Names mark the locations of twenty Mayan constellations.

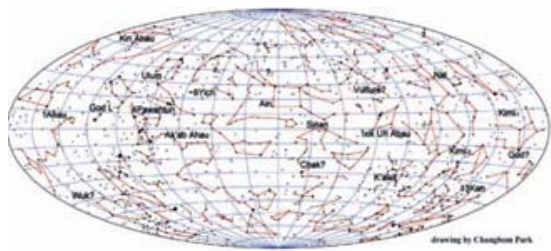

Figure 11. Venus and constellations on the sky in the morning of April 14, 1229, and in the evening of April 15, 1230 appearing in page 46 and 47. In the morning of April 14, 1229, Venus was east near from horizon, and the region near Virgo (Vir) and Bootes (Boo) was at the opposite direction, west. In the evening of April 15, 1230, Venus was at west; the region near Virgo (Vir) and Bootes (Boo) was at the opposite direction, east. A constellation 'Kimi' is named at both days.

We have allocated the specific part of the sky corresponding to each Mayan constellation name in terms of the modern constellations. The final results are listed in Table 1. There is one Mayan constellation named twice, which we have distinguished from each other as Kimi-1 and Kimi-2. They are identified with Virgo-Bootes and Ophiucus-Scorpius, respectively. Even though their separation 
is large, we can assign the constellation Kimi to the whole area consisting of both, since Kimi-1 and Kimi-2 are located right next to each other.

\section{Meanings of 'tie' and 'feed' and the Summary of Results.}

\subsection{Meanings of 'tie' and 'feed'}

When we identify Mayan constellations with the modern constellations using the pairs of records on celestial events, the meanings of 'tie' in panel $\mathrm{C}$ and 'feed' in panel $\mathrm{F}$ became manifest. The records in panels $\mathrm{C}$ and $\mathrm{F}$ are found to correspond to the actual situations in the sky as described in Table 2.

Table 2. Actual situation corresponding to the expression on the movement of Venus from page 46 to 50 of the Dresden Codex. C1, C2, C3, and C4 are constellations.

\begin{tabular}{|c|c|c|}
\hline & Expression in Dresden Codex & Actual Situation \\
\hline \multirow{2}{*}{ (a) } & Venus ties to the North, $\mathrm{C1}$ & $\begin{array}{l}\text { The Evening Venus is setting, and C1 is setting together in } \\
\text { Northwest }\end{array}$ \\
\hline & C1 feeds Venus at the North & $\begin{array}{l}\text { ( } 220 \text { days later) The Evening Venus is setting, and C1 is } \\
\text { nsing in Northeast }\end{array}$ \\
\hline \multirow{2}{*}{ (b) } & Venus ties to the West, C2 & $\begin{array}{l}\text { The Evening Venus is setting in the West, and C2 is rising } \\
\text { in East }\end{array}$ \\
\hline & C2 feeds Venus at the West & $\begin{array}{l}\text { ( } 380 \text { days later) The Moming Venus is rising, and C2 is } \\
\text { setting in West }\end{array}$ \\
\hline \multirow{2}{*}{ (c) } & Venus ties to the South, $\mathrm{C} 3$ & $\begin{array}{l}\text { The Morning Venus is rising, and C3 is rising together in } \\
\text { Southeast }\end{array}$ \\
\hline & C3 feeds Venus at the South & $\begin{array}{l}\text { (138 days later) The Moming Venus is rising, and C3 is } \\
\text { setting in Southwest }\end{array}$ \\
\hline \multirow{2}{*}{ (d) } & Venus ties to the East, C4 & $\begin{array}{l}\text { The Morning Venus is rising in the East, and C4 is setting } \\
\text { in West }\end{array}$ \\
\hline & C4 feeds Venus at the East & $\begin{array}{l}\text { ( } 366 \text { days later) The Evening Venus is setting, and C4 is } \\
\text { nising in East }\end{array}$ \\
\hline
\end{tabular}

From above we can notice that the verbs 'tie' and 'feed' are used in the following way. The word 'tie' is used when the direction of Venus is indicated. The Evening Venus in the West 'ties' to the West or Northwest and the Morning Venus in the East 'ties' to the East or Southeast. Note that the subject of the verb 'tie' is always Venus. On the other hand, the word 'feed' is used when a constellation located in the opposite direction to Venus is being mentioned. The subject of 'feed' is always a constellation. Constellations in East or Northeast feed the Evening Venus in the West, and those in West or Southwest feed the Morning Venus in the East.

\subsection{Results}

Our findings can be best summarized by Table 3 , which lists the contents of the Dresden Codex from page 46 to 50 , covering one Venus Grand Cycle of 104 years.

PARK Y CHUNG / IDENTIFICATION OF POSTCLASSIC MAYA CONSTELLATIONS 
The left-most side of Table 3 is the left part of the original text of Dresden Codex, and the middle is the simplified deciphered hieroglyphic text. In the right hand side we give specific dates corresponding to the events in the Venus calendar assuming that the first date is February 6, 1228 and decipher glyphs in panels C and $\mathrm{F}$ in terms of actual phenomena played by the celestial bodies.

\section{Discussion}

From the fact that Mayans developed and used the Venus calendar, one can infer that it was very important for them to know when Venus appears in the morning or in the evening and to predict the period that Venus was not visible. Through this study, we recognize Mayan people understood the diurnal and annual motions of the Sun, Venus, and constellations. Mayans marked the beginning point of the Venus cycle by using regularity of the relative locations among the Sun, Venus, and constellations, and invented the time intervals of $236,90,250$ and 8 days corresponding to four Venus phases.

Mayans also had their own system to describe the changing sky. They seem to have used the astronomical terminology K'alah (meaning "tie") and Tzeni (meaning "feed") to depict the relative movement of Venus and constellations. Mayans marked their own constellation in the sky to describe the location of Venus' appearance relative to constellations at dawn or dusk. With this way to observe a specific constellation on the same side or on the other side of Venus the Mayans could recognize the special dates within Venus phases.

We also note that the Venus calendar in Dresden Codex is not a calendar based only on the motion of Venus because one Venus cycle of the calendar actually comprises five Venus calendar years which is almost eight solar years. Namely, the calendar in Dresden Codex is a Venus-Solar calendar. Our work focuses on this possibility. Correspondingly, it was conceivable that the calendar was made to work in conjunction with the periodic appearance of constellations on the sky. Observing the sky one can find a certain date in Tzolk'in and Haab calendar written in Venus pages. However, there is one thing to remember. The constellations that can be used to designate the special dates are changing slowly from one Grand Venus cycle (about 104 years) to another. Even though the Venus calendar itself requires correction of only 5.2 days after one Grand cycle, the companion constellations to Venus run off by 30.4 days or 30 degrees. Therefore, the actual constellations corresponding to the Mayan constellation names in the Dresden Codex should be modified after a few cycles. The modification for the next cycle is small and predictable. But if people of Late Classic Maya, flourished from about 600 to 900 A.D., used the same names, their constellations corresponding to the names would have been quite different from those of Postclassic Mayans.

On the other hand, it should be noted that the sentence structure of the Venus chapter of Dresden Codex has an interesting feature. The sentences start with the 
date and then record the events, and include drawings of the symbolic figures. It is a text style very similar to what is seen in stelae or relives. The text is written from top to bottom following the stelae style, at the same time it is characterized by connecting side ways, the modern text style. Each column of Venus pages from 46 to 50 lists three calendar dates. The first one appears at the beginning of the column, but the dates related to the special events are given not before but after the corresponding sentences. It was because the calendar dates were intended to indicate the interval of days and not the certain dates. In this way the Mayans could use the calendar very creatively. In each page the vertical writing tells about the change of the constellations keeping time with the movement of Venus. The horizontal writing tells about the changes of the Venus phase and trajectory. When it completes one Venus cycle, and a new Venus cycle consisting of four phases begins. The cycle continues without end. Writing vertically and horizontally it maximizes the use of spaces of the text, and at the same time the description is of visual style, letting one to imagine the revolving of the sky, by connecting one end to the other end. It also shows the Mayan's attitude of observation and study of celestial movement. It represents the basic philosophy of Mesoamerican culture; there is no beginning or ending of the universe and life is circling endlessly by connecting one thing to another. Dresden Codex is valued not only as a practical science book with information on Venus but also as a window to peer into creativity of Mayans, and is a beautiful piece of Mayan literature.

\section{References}

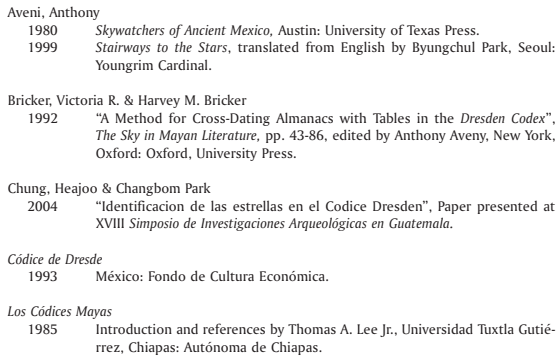


Colabretta, M.R. \& Greisen E.W.

2002 Astronomy and Astrophisics, 395, 1077.

Knorozov, Yurii

1982 Maya Hieroglyphic Codices, translated from the Russian by Sophie D. Coe, Publication No. 8, Institute for Mesoamerican Studies, State University of New York at Albany.

Landa, Diego de

1978 Yucatan before and after the Conquest, ttranslated with notes by William Gates, New York: Dover Publications, INC.

Lounsbury, Floyd G.

1992a "A Derivation of the Mayan-to Julian Calendar Correlation from the Dresden Codex Venus Chronology" The Sky in Mayan Literature, pp. 184-206, edited by Anthony Aveny, Oxford New York, Oxford: University Press.

1992b "A Solution for the Number 1.5.5.0 of the Mayan Venus Table" The Sky in Mayan Literature, pp. 207-215, edited by Anthony Aveny, New York, Oxford: Oxford University Press.

Paxton, Merideth

2001a Yucatán a través de los siglos, Memorias del 49 Congreso Internacional de Americanistas, Quito, Ecuador 1997, pp. 95-116, coordinated by Ruth Gubler and Patricia Martel. Mérida, Yucatán: ediciones de la Universidad Autónoma de Yucatán.

2001b The Cosmos of the Yucatec Maya: Cycles and Stenos from the Madrid codex, Albuquerque: University of Texas press.

Schele, Linda y Nikolai Grube

1997 The Dresden Codex, Notebook for the $21^{\text {st }}$ Maya Hieroglyphic Forum at Texas, The University of Texas at Austin. 


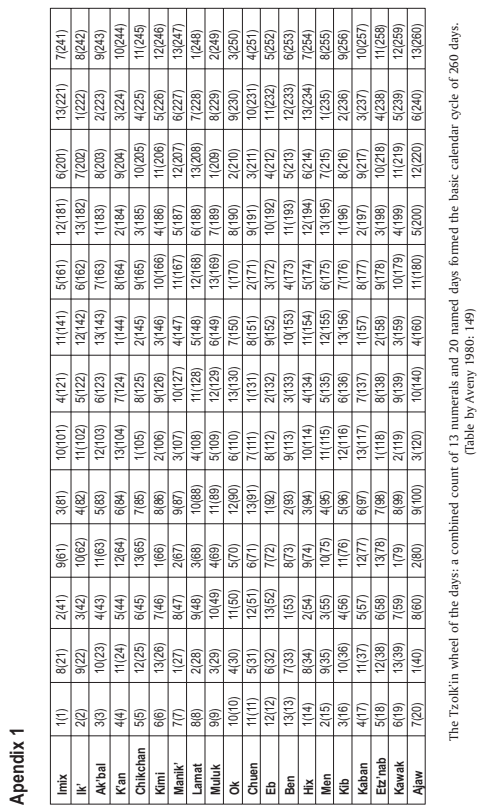




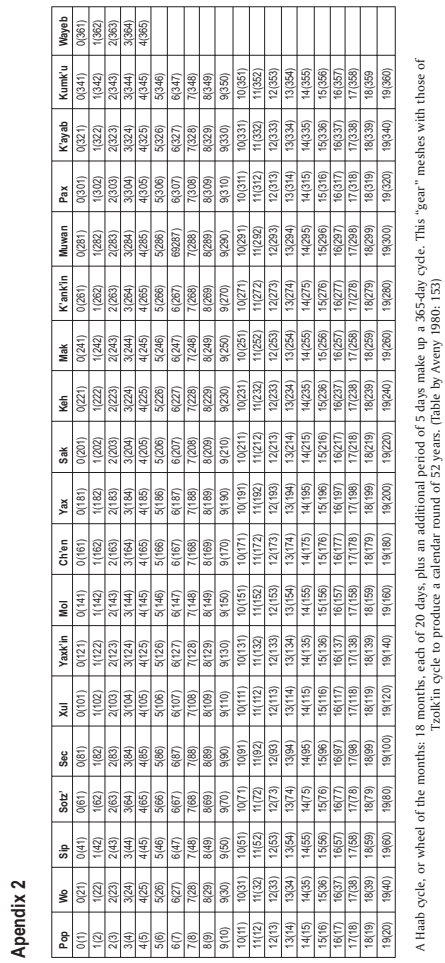

